\title{
Biometria de frutos e qualidade fisiológica de sementes de Sesamum indicum oriundas de plantas adubadas com esterco bovino ${ }^{1}$
}

\author{
Ronimeire Torres da Silva ${ }^{2}$; Maria de Fátima de Queiroz Lopes ${ }^{3}$; Francisco Hélio Alves de Andrade ${ }^{4}$ \\ Antonio Caubí Marcolino Torres ${ }^{5}$; Miguel Avelino Barbosa Neto ${ }^{6}$; Rodrigo Garcia Silva Nascimento
}

Resumo: O gergelim está entre as dez principais oleaginosas produzidas no mundo. Para uma alta produtividade torna-se necessário o uso de sementes com elevada qualidade fisiológica. Plantas nutridas geralmente produzem sementes vigorosas. Objetivou-se com esta pesquisa avaliar a biometria dos frutos e a qualidade fisiológica de sementes de gergelim de plantas adubadas com esterco bovino. $\mathrm{O}$ experimento para produção das sementes foi realizado no setor de Agricultura da Universidade Federal do Ceará (UFC), FortalezaCE, em blocos ao acaso. As plantas foram adubadas com quatro doses de esterco bovino (0, 20, 40 e $\left.60 \mathrm{t} \mathrm{ha}^{-1}\right)$. Após a colheita foi aferida a biometria dos frutos, o potencial de germinação e o vigor das sementes. O aumento nas doses de esterco bovino proporcionou frutos maiores. A germinação, primeira contagem de germinação e o índice de velocidade de geminação apresentou incremento quando as sementes foram provenientes de plantas adubadas. As sementes de plantas adubadas com esterco bovino originaram plântulas mais vigorosas, apresentando comprimento e massa seca com valores superiores quando comparadas com as plantas que não foram adubadas.

Palavras-chave: Adubação orgânica; Gergelim; Germinação; Vigor de sementes.

\section{Fruit biometry and physiological quality of Sesamum indicum seeds from plants fertilized with bovine manure}

\begin{abstract}
Sesame is among the top ten oilseeds produced in the world. For high productivity it is necessary to use seeds with high physiological quality. Nourished plants generally produce vigorous seeds. The objective of this research was to evaluate the fruit biometry and the physiological quality of sesame seeds of plants fertilized with bovine manure. The experiment for seed production was carried out in the agricultural sector of the Federal University of Ceará (UFC), Fortaleza-CE, in randomized blocks. The plants were fertilized with four doses of bovine manure $(0,20,40$ and $60 \mathrm{t}$ ha-1). After the harvest, fruit biometry, germination potential and seed vigor were measured. The increase in the doses of cattle manure provided larger fruits. The germination, first germination count and the rate of twinning increased when the seeds were obtained from fertilized plants. The seeds of plants fertilized with bovine manure gave more vigorous seedlings, presenting length and dry mass with higher values when compared with the plants that were not fertilized.
\end{abstract}

Keywords: Organic fertilization; Sesame; Germination; Seed vigor

\footnotetext{
${ }^{1}$ Submetido em 29/10/2018 e aprovado em 30/01/2019

${ }^{2}$ Doutora em Agronomia; Universidade Federal da Paraíba (UFPB), Centro de Ciências Agrária, Programa de Pós-Graduação em Agronomia, Areia-PB, CEP: 58.397-000; E-mail: ronimeiretorres@ hotmail.com

${ }^{3}$ Mestre em Agronomia; Estudante de Doutorado; Universidade Federal da Paraíba (UFPB), Centro de Ciências Agrária, Programa de PósGraduação em Agronomia, Areia-PB, CEP: 58.397-000; E-mail: fatimaqueiroz0@ gmail.com

${ }^{4}$ Mestre em Agronomia; Estudante de Doutorado; Universidade Federal de Lavras (UFLA), Departamento de Biologia, Programa de PósGraduação em Fisiologia Vegetal, Lavras-MG, CEP. 37.200-000; E-mail: helioalvesuepb@ gmail.com

${ }^{5}$ Geográfo; Professor da Rede Estadual do Rio Grande do Norte, 13 ${ }^{\text {a }}$ Dired, Apodi-RN, CEP: 59.700-000; E-mail: caubitorres@ @otmail.com

${ }^{6}$ Mestre em Agronomia; Universidade Federal da Paraíba (UFPB), Centro de Ciências Agrária, Programa de Pós-Graduação em Agronomia, Areia-PB, CEP: 58.397-000; E-mail: miguelavelinoneto18@gmail.com

${ }^{7}$ Ciências Agrárias; Estudante de Doutorado; Universidade Federal da Paraíba (UFPB), Centro de Ciências Agrária, Programa de PósGraduação em Agronomia, Areia-PB, CEP: 58.397-000; E-mail: rodrigo_garciasilva@ @otmail.com
} 


\section{Introdução}

O gergelim (Sesamum indicum L.) é uma oleaginosa da família Pedaliaceae, possui como centro de origem a Ásia ou África (Beltrão et al., 2001). É uma cultura muito difundida no Brasil, principalmente na região Nordeste, por apresentar adaptabilidade às condições edafoclimáticas de clima quente, bem como resistência à seca e facilidade de cultivo. É dotado de potencial econômico, tanto no mercado interno quanto externo em decorrência principalmente da elevada qualidade do óleo que produz, com aplicações nas indústrias alimentícias e óleoquímica, sendo que esta última se encontra em plena ascensão, com aumento anual aproximado de $15 \%$ na quantidade de produtos industrializáveis para consumo (Beltrão et al., 2013). No cenário mundial a África conta com mais de $40 \%$ da produção de sementes de gergelim do mundo, onde a cultura tem amplo cultivo como em regiões no Sahel da África Ocidental, que na última década a produção mais que dobrou nesta área impulsionando $\mathrm{o}$ desenvolvimento local (Dossa et al., 2017).

Dependendo da variedade, a semente de gergelim pode conter $21,83 \%$ de proteína, além de ser considerada rica em aminoácidos sulfurados, característica rara entre as proteínas de origem vegetal (Queiroga e Silva, 2008), isso alavancou o consumo de gergelim dos brasileiros nos últimos anos, requerendo por parte dos produtores medidas que aumentem a produtividade e a qualidade do produto final. $\mathrm{O}$ uso de sementes de elevada qualidade fisiológica surge como uma alternativa para aumento na produção (Beltrão e Vieira, 2001), pois de acordo com Carvalho e Nakagawa (2012) a utilização de sementes com qualidade genética, fisiológica, física e sanitária é um dos fatores mais importantes para o sucesso no estabelecimento de uma determinada cultura.

Semente de alta qualidade é aquela que apresenta elevada germinação e vigor, com grau de umidade adequado e de boa aparência externa. Esses fatores, quando coexistem podem proporcionar maior homogeneidade do lote de sementes, elevado vigor de plantas e, consequentemente, maior qualidade $\mathrm{e}$ produtividade dos cultivos (Lacerda, 2007). A utilização de adubo orgânico durante a produção das sementes pode melhorar sua qualidade, visto que plantas que se desenvolvem em condições nutricionais ideais tem maior potencial para produção de sementes bem formadas e vigorosas (Macedo et al., 2018).

Isso ocorre por que a adubação proporciona melhor desenvolvimento vegetativo da planta e melhores condições de suprimento dos frutos e sementes que serão formados (Quadros et al., 2012). Quando comparados com os adubos químicos, os adubos orgânicos apresentam a liberação mais lenta dos nutrientes, principalmente o nitrogênio e o fósforo, sendo disponibilizado durante todo o ciclo da cultura (Magro et al., 2010).

Como no período de formação das sementes são exigidas quantidades consideráveis de nutrientes, o uso dos adubos de origem orgânica, em campos de produção, poderia contribuir para a obtenção de material de reprodução com maior qualidade (Quadros et al., 2012).

O esterco bovino é dentre os insumos orgânicos existentes a fonte mais utilizada, especialmente em solos pobres em matéria orgânica, pois apresenta em torno de 55\% de matéria orgânica e de fácil aquisição em pequenas e grandes propriedades da região Nordeste (Cavalcante et al., 2012). Atua no solo, podendo melhorar as características físicas e químicas, sendo capaz de reduzir a plasticidade e a coesão, aumentar a capacidade de retenção de água e aeração, permitindo maior penetração e distribuição das raízes (Malavolta e Romero, 1975).

O objetivo com este trabalho foi avaliar a biometria de frutos e a qualidade fisiológica de sementes de gergelim (Sesamum indicum) oriundas de plantas adubadas com esterco bovino.

\section{Material e Métodos}

O experimento para obtenção das sementes foi realizado seguindo as recomendações para a produção da cultura (Queiroga et al., 2007), no setor de Agricultura ( $3^{\circ} 43^{\prime} 2^{\prime \prime} \mathrm{S}$, de latitude, $38^{\circ}$ 32 ' $35^{\prime}$ W, de longitude e $21 \mathrm{~m}$ de altitude) da Universidade Federal do Ceará (UFC), FortalezaCE. O clima da região, segundo a classificação climática de Köppen (1948) é do tipo AW', tratando-se de um clima tropical chuvoso. Antes do cultivo foi coletada amostra composta da camada superficial $(0-20 \mathrm{~cm})$ do solo e analisada quantos aos atributos de fertilidade e físicos (Tabela 1). 
Tabela 1 Fertilidade e atributos físicos, na camada de 0-20 $\mathrm{cm}$ de profundidade, do solo utilizado para a produção das sementes

\begin{tabular}{|c|c|c|c|c|c|c|c|c|c|c|c|c|}
\hline \multicolumn{13}{|c|}{ Atributos de Fertilidade } \\
\hline $\mathrm{pH}$ & $\mathrm{Ca}^{2+}$ & $\mathrm{Mg}^{2+}$ & $\mathrm{K}^{+}$ & $\mathrm{Al}^{3+}$ & $\mathrm{Na}^{+}$ & $\mathrm{H}^{+}+\mathrm{Al}^{3+}$ & SB & CTC & $\mathrm{P}$ & COT & $\mathrm{V}$ & M.O. \\
\hline $\mathrm{H}_{2} \mathrm{O}$ & & & & $---\mathrm{cn}$ & $\mathrm{ol}_{\mathrm{c}} \mathrm{kg}^{-1}$ & ---------- & & ----- & $\mathrm{mg} \mathrm{kg}^{-1}$ & $\mathrm{~g} \mathrm{~kg}^{-1}$ & ------- & ------ \\
\hline 6,12 & 1,40 & 0,80 & 0,94 & 0,10 & 0,03 & 1,00 & 3,17 & 4,17 & 16,10 & 1,85 & 76,05 & 0,65 \\
\hline \multicolumn{13}{|c|}{ Atributos Físicos } \\
\hline Areia & \multicolumn{3}{|c|}{$\begin{array}{ll}\text { Silte } & \text { Argila } \\
\mathrm{g} \mathrm{kg}^{-1} & \end{array}$} & \multicolumn{3}{|c|}{ Densidade do solo } & & sidade & partícula & \multicolumn{3}{|c|}{ Classe textural } \\
\hline 906,9 & \multicolumn{2}{|c|}{60,6} & 32,6 & \multicolumn{3}{|c|}{1,6} & & \multicolumn{2}{|c|}{2,6} & \multicolumn{3}{|c|}{ Arenosa } \\
\hline
\end{tabular}

Os tratamentos contaram de quatro doses de esterco bovino curtido $\left(0,20,40\right.$, e $\left.60 \mathrm{t} \mathrm{ha}^{-1}\right)$ distribuídos em 4 blocos casualizados. As parcelas foram formadas por 18 linhas espaçadas entre si em $0,7 \mathrm{~m}$ sendo as 16 linhas centrais a parcela útil. O esterco utilizado possuía $116,74 \mathrm{~g}$ $\mathrm{kg}^{-1}$ de carbono orgânico, $7,91 \mathrm{~g} \mathrm{~kg}^{-1}$ de nitrogênio e relação $\mathrm{C}: \mathrm{N}$ de 1:15. A aplicação do esterco foi em sulcos de $10 \mathrm{~cm}$ de profundidade.

O material genético utilizado foi semente de gergelim cv. BRS Seda cedida pela EMBRAPA, por possuir sementes de coloração clara, sendo mais aceitáveis pelo comércio de sementes. A cultivar apresenta ciclo precoce e é adaptada às condições de clima do semiárido.

A semeadura foi realizada em covas com profundidade de $2 \mathrm{~cm}$, espaçadas em $0,20 \mathrm{~m}$ entre si e $0,70 \mathrm{~m}$ entre linhas, deixando-se duas plantas por cova após o desbaste realizado 20 dias após a semeadura (142.857 plantas por hectare).

As plantas foram irrigadas, diariamente, utilizando sistema de aspersão. O controle das plantas invasoras foi realizado por meio de capinas manuais sempre que necessário. A colheita foi realizada aos 90 dias após a semeadura, na qual foram colhidas, da área útil, 12 plantas ao acaso realizando o corte na altura de inserção dos primeiros frutos $(35 \mathrm{~cm}$ de altura em relação à superfície do solo).

Depois de colhidos, foi realizada a avaliação da biometria dos frutos através do comprimento e largura, mensurados com um paquímetro digital utilizando-se quatro repetições de 50 frutos. Para determinar o comprimento considerou-se toda a extensão da cápsula no sentido longitudinal e o diâmetro da cápsula (largura) foi determinado na porção mediana no sentido transversal. Após as medições, os frutos foram mantidos em secador elétrico com circulação de ar forçada, a $30-35^{\circ} \mathrm{C}$ por quatro dias. Em seguida foram acondicionados em sacos plásticos e analisados no Laboratório de Análise de Sementes (LAS), da Universidade Federal do Ceará (UFC), onde determinou-se o teor de umidade das sementes pelo método de estufa a $105 \pm 3^{\circ} \mathrm{C}$ durante 24 horas (Brasil, 2009). Em seguida foram realizados os testes para avaliar a qualidade fisiológica e vigor das sementes.

A qualidade fisiológica das sementes foi avaliada através dos testes de Germinação (G\%) realizado com 4 repetições de 50 sementes. Foi usado o papel germitest como substrato, utilizando 3 folhas umedecidas com uma quantidade de água equivalente a 2,5 vezes o peso seco do papel. Os rolos de papel foram acondicionadas em germinadores tipo Biochemical Oxigen Demand (B.O.D) a $25^{\circ}$ C, em fotoperíodo de 12 horas. As contagens foram efetuadas aos três (Primeira Contagem e Germinação) e seis dias após a semeadura, de acordo com os critérios estabelecidos nas Regras para Análise de Sementes (Brasil, 2009), e os resultados expressos em porcentagem de plântulas normais pela fórmula.

Índice de Velocidade de Germinação (IVG), realizado simultaneamente com o teste de germinação, as plântulas foram avaliadas diariamente, na mesma hora, a partir do segundo dia após a semeadura. As avaliações foram feitas até a última contagem (sexto dia após a semeadura). Para o cálculo foi usada a fórmula proposta por Maguire (1962), IVG $=\mathrm{G}_{1} / \mathrm{N}_{1}+$ $\mathrm{G}_{2} / \mathrm{N}_{2}+\mathrm{G}_{3} / \mathrm{N}_{3}+\ldots .+\mathrm{G}_{\mathrm{n}} / \mathrm{N}_{\mathrm{n}}$, onde: $\mathrm{IVG}=$ Índice de Velocidade de Germinação; $\mathrm{G}_{1}, \mathrm{G}_{2}, \mathrm{G}_{\mathrm{n}}=$ número de plântulas normais computadas na primeira, segunda e última contagem; $\mathrm{N}_{1}, \mathrm{~N}_{2}, \mathrm{~N}_{\mathrm{n}}=$ número de dias de semeadura da primeira, segunda e última contagem.

Comprimento de Plântulas (CP), no final do teste de germinação foram escolhidas 15 plântulas ao acaso de cada repetição. Com o 
auxílio de uma régua milimétrica foi realizada a medição da base do colo até a inserção da última folha, o resultado foi expresso em $\mathrm{cm}$.

Massa Seca de Plântulas (MSP), depois de feitas as medições, as plântulas de cada tratamento foram colocadas em sacos de papel e levadas para estufa regulada a $65^{\circ} \mathrm{C}$ por 24 horas e, em seguida, pesadas em balança de precisão e o resultando expresso em g.plântulas ${ }^{-1}$ (Nakagawa, 1999).

Os dados foram submetidos ao teste $\mathrm{F}$, e análise de regressão de primeiro e segundo grau a 1 e 5\% de significância. Com auxílio do Software Sisvar.

\section{Resultados e Discussão}

$\mathrm{O}$ teor de água das sementes variou de 8 a 9,2\% (Tabela 2), esses valores ainda são considerados alto para a cultura, sendo que após a colheita de gergelim o ideal é reduzir o teor de água das sementes até 4,5\% (Queiroga e Silva, 2008; Queiroga, 2010).

Tabela 2 Teor de água das sementes Gergelim (Sesamum indicum L.) oriundas de plantas adubadas com doses de esterco bovino

\begin{tabular}{cc}
\hline $\begin{array}{c}\text { Doses de esterco } \\
\left(\mathrm{t} \mathrm{ha}^{-1}\right)\end{array}$ & $\begin{array}{c}\text { Teor de umidade das sementes } \\
(\%)\end{array}$ \\
\hline 0 & 9,2 \\
20 & 9,0 \\
40 & 8,5 \\
60 & 8,0 \\
\hline
\end{tabular}

$\mathrm{Na}$ análise dos frutos de gergelim, nota-se que a medida que aumentou-se as doses de esterco bovino houve um aumento na biometria dos frutos, para o comprimento dos frutos houve diferença significativa a $1 \%$ de probabilidade nas equações de $1^{\circ}$ e $2^{\circ}$ grau, enquanto que para a largura dos frutos houve efeito a $1 \%$ apenas na equação de $1^{\circ}$ grau. (Figuras 1). A largura dos frutos passou de $6,2 \mathrm{~mm}$ na dose zero (controle), para o valor máximo de $8,42 \mathrm{~mm}$ quando as plantas foram adubadas com a dose $43 \mathrm{t} \mathrm{ha}^{-1}$. No comprimento dos frutos, testemunha obteve $18,29 \mathrm{~mm}$, esse valor aumentou até a dose $52 \mathrm{t} \mathrm{ha}^{-}$ ${ }^{1}$ de esterco obtendo-se $29,76 \mathrm{~mm}$. Esses dados são importantes visto que frutos maiores possuem uma maior quantidade de semente, ou seja, maior produtividade. Esses valores estão dentro do padrão para frutos de gergelim, que segundo Beltrão et al. (2013) os frutos do gergelim são cápsulas pilosas, seu tamanho pode variar de 2 a
$8 \mathrm{~cm}$ de comprimento e diâmetro de 0,5 a $2 \mathrm{~cm}$, a depender da variedade e das condições de cultivo.

O estudo com biometria de frutos é importante para identificar se existe alguma relação entre a variabilidade genética de uma população com fatores ambientais e nutricionais. Essa variável pode ser usada em programas de melhoramento genético, pois disponibiliza informações importantes para a caracterização dos aspectos ecológicos como o tipo de dispersão, agentes dispersores e estabelecimento das plântulas (Moreira et al., 2016; Matos et al., 2017; Pontes et al., 2018).

$\mathrm{Na}$ avaliação da qualidade fisiológica pelo teste de germinação, observa-se que a germinação passou de 97\% (testemunha) para 99\% na dose de $32 \mathrm{t} \mathrm{ha}^{-1}$ de esterco bovino, dessa forma não diferindo estatisticamente (Figura 2A). Embora os adubos orgânicos apresentam liberação mais lenta dos nutrientes (Magro et al., 2010), no período de formação das sementes esses nutrientes foram liberados do solo para efetiva nutrição das plantas. Diferindo dos observados por Lopes et al. (2004) onde avaliando a qualidade física e fisiológica de sementes de milho (Zea mays) em função da adubação mineral e orgânica, verificaram aumento na germinação das sementes quando essas foram produzidas de plantas adubadas (95\% e 70\%), plantas adubadas com $250 \mathrm{~kg}$ de 4-14-8 + $100 \mathrm{~kg}$ de sulfato de amônio e plantas sem adubação orgânica e mineral, respectivamente.

Para a primeira contagem de germinação, realizada ao terceiro dia após a instalação do teste, não houve diferença significativa (Figura 2B), demostrando que essa variável pode ter sido influenciada por condições ambientais ou outros fatores intrínsecos ligados ao genótipo. Resultados semelhantes foram observados por Dutra et al. (2012), onde avaliando a produtividade e qualidade fisiológica de sementes de feijão caupi (Vigna unguiculata L. ) em função da adubação nitrogenada, não observaram diferença para a variável em estudo, obtendo 97,5\% na testemunha, 99,5 e 99\% de plântulas normais originadas de plantas adubadas com $15 \mathrm{e}$ $30 \mathrm{~kg}$ de nitrogênio na fundação, enquanto que as plantas adubadas na cobertura ( 15 e $30 \mathrm{~kg}$ de N) apresentaram sementes com 96 e $91 \%$ de plântulas normais, respectivamente. Ainda segundo os autores esse resultado deve-se ao fato de diversos fatores interagem e interferem no 
potencial germinativo das sementes como, por exemplo, a cultivar utilizada, condições ambientais e as técnicas utilizadas durante e após o cultivo, não somente a adubação.
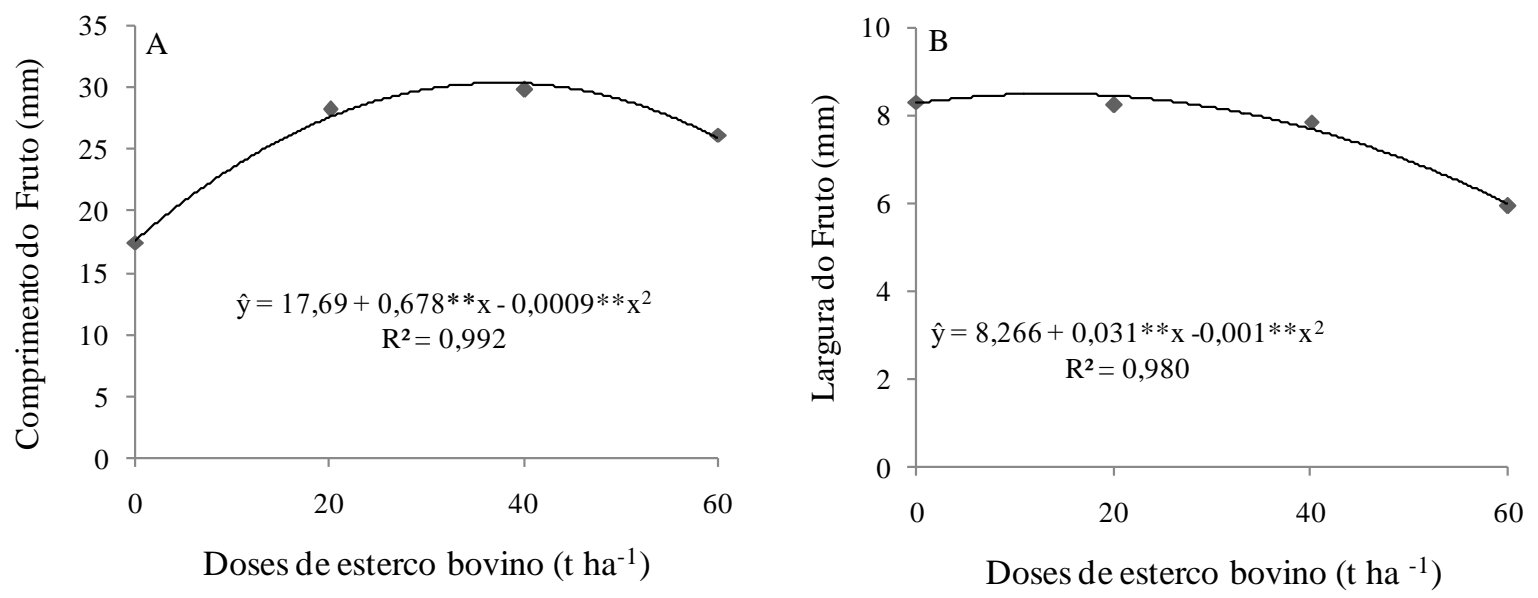

Figura 1 Largura (A) e comprimento (B) de frutos de gergelim (Sesamum indicum L.) oriundas de plantas adubadas com doses de esterco bovino.
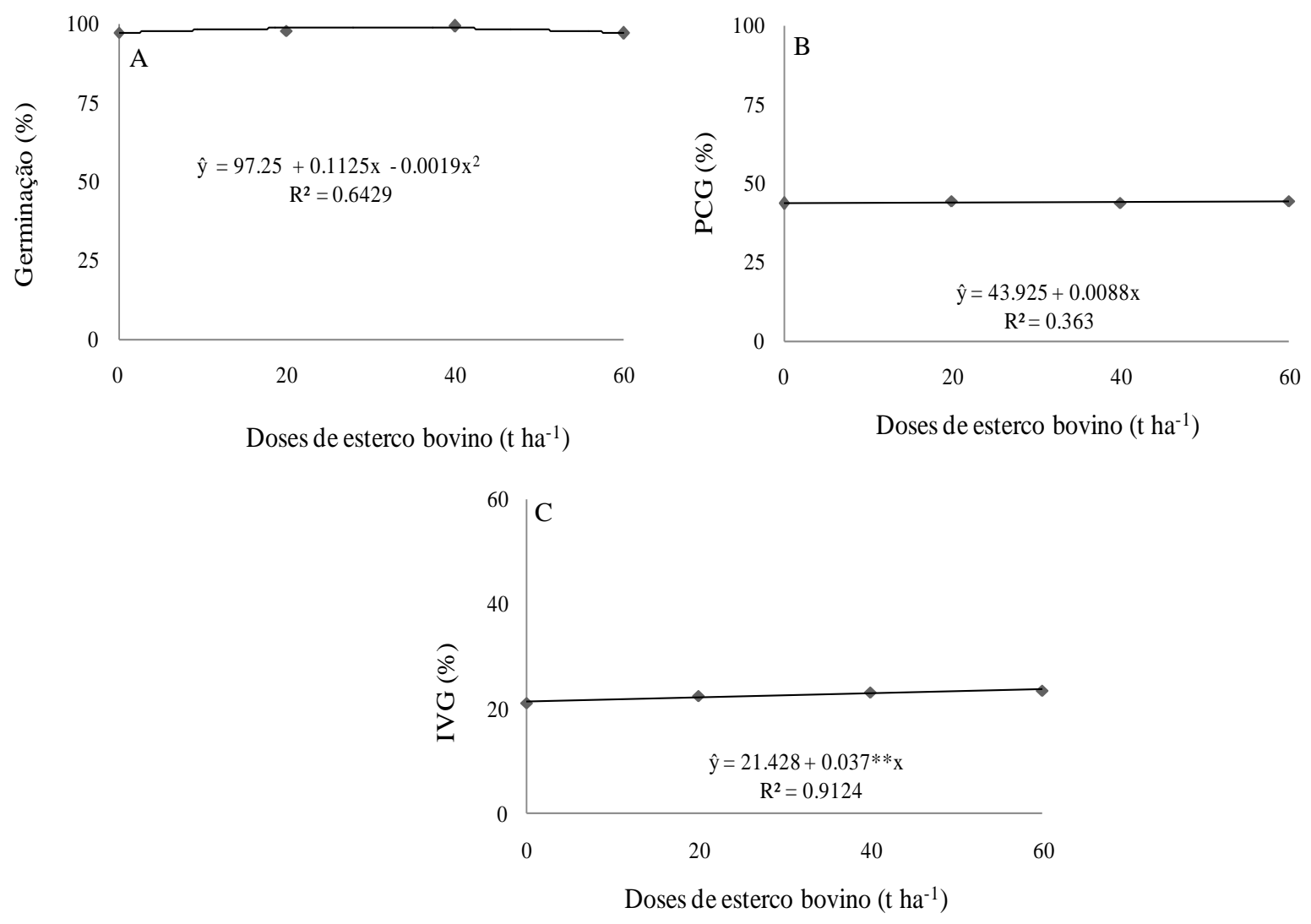

Figura 2 Germinação (A), Primeira Contagem de Germinação (B), Índice de Velocidade de Germinação (C) de sementes e plântulas de Gergelim (Sesamum indicum L.) oriundas de plantas adubadas com doses de esterco bovino. 
Para o variável índice de velocidade de germinação nota-se que houve diferença significativa a $1 \%$ de probabilidade para a equação de $1^{\circ}$ grau, ocorrendo um leve acréscimo entre a testemunha $(21 \%)$ para $24 \%$ quando as plantas foram adubadas com $60 \mathrm{t} \mathrm{ha}^{-1}$ de esterco bovino (Figura 2C). Costa Júnior (2015) avaliando a qualidade fisiológica de sementes de quinoa (Chenopodium quinoa willd.) produzidas em solo com adubações orgânicas, também observou incremento na velocidade de germinação quando aplicou esterco bovino com cinza, em comparação somente ao esterco, sendo

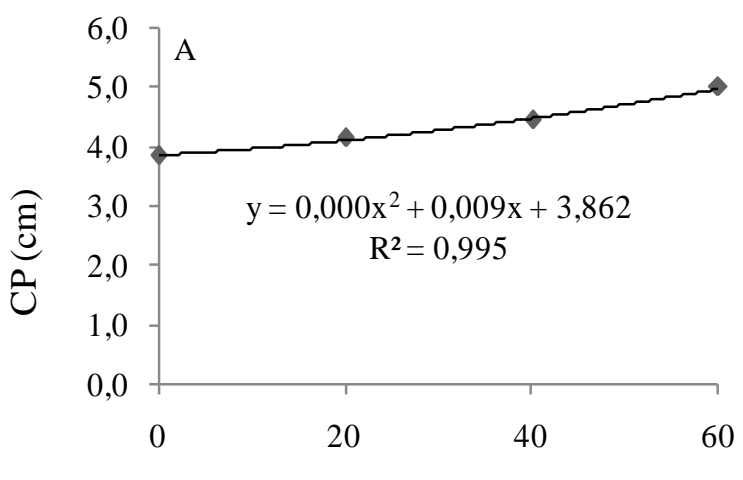

Doses de estreco bovino $\left(\mathrm{t} \mathrm{ha}^{-1}\right)$ essa uma possível alternativa para aumentar a velocidade de germinação das sementes.

A medida que aumentou-se a dose de esterco bovino houve um acréscimo no comprimento das plântulas, havendo diferença significativa a $1 \%$ de probabilidade nas equações de 1 e $2^{\circ}$ grau, sendo o ponto máximo atingido nas sementes oriundas de plantas adubadas com $60 \mathrm{t} \mathrm{ha}^{-1}$ (5 $\mathrm{cm}$ ), enquanto que o controle obteve plântulas com 3,9 cm (Figura 3A), observando-se nesse caso, maior chance de estabelecimento da plântula em condições de campo, quando fornecido uma boa nutrição para planta.

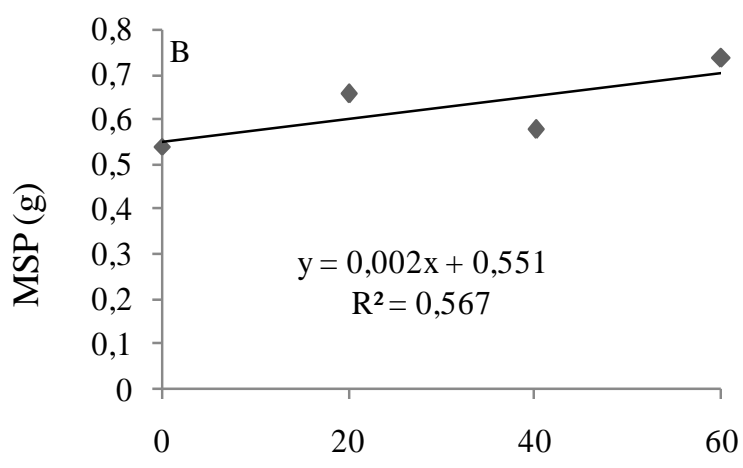

Doses de esterco bovino ( $\left.\mathrm{tha}^{-1}\right)$

Figura 3 Comprimento de Plântulas (A) e Massa Seca de Plântulas (B) de sementes e plântulas de Gergelim (Sesamum indicum L.) oriundas de plantas adubadas com doses de esterco bovino.

Diferindo dos resultados obtidos por Carvalho et al. (2001) em que avaliando a produtividade e qualidade de sementes de feijoeiro (Phaseolus vulgaris L.) sob influência de parcelamento e fontes de nitrogênio, não observaram efeito no desenvolvimento inicial de plântulas de feijão, produzidas a partir de plantas cultivadas em diferentes condições de adubação.

O teste de vigor é de suma importância, pois tem como princípio que plântulas com maior comprimento são mais vigorosas (Nakagawa, 1999). Isso acontece devido a translocação das reservas dos tecidos de armazenamento para o crescimento do eixo embrionário (Guedes et al., 2015), ou seja, mesmo a germinação sendo igual as sementes produzidas em plantas adubadas com $60 \mathrm{t} \mathrm{ha}^{-1}$ de esterco bovino possuem maior quantidade de reservas, que são translocadas para as plântulas.
A massa seca das plântulas acompanhou o mesmo comportamento do comprimento, pois plântulas maiores resultam, em geral, maior massa seca (Figura 3B). Sendo o valor máximo $(0,74 \mathrm{~g})$ alcançado nas plântulas oriundas de plantas adubadas com $60 \mathrm{t} \mathrm{ha}^{-1}$, e o valor mínimo no controle $(0,54 \mathrm{~g})$. Diferindo dos resultados observados por Dutra et al. (2012) onde avaliando a produtividade e qualidade fisiológica de sementes de feijão caupi (Vigna unguiculata L.) Walp.em função da adubação nitrogenada, não constatou diferença para essa variável, com valores variando de $0,188 \mathrm{~g}$ no controle e $0,190 \mathrm{~g}$ quando as plantas foram adubadas com $30 \mathrm{~kg}$ de $\mathrm{N}$ na cobertura.

\section{Conclusão}

Plantas de gergelim (Sesamun indicum) adubadas com 43 e $52 \mathrm{t} \mathrm{ha}^{-1}$ de esterco bovino 
produzem frutos com maior largura e comprimento, respectivamente;

A maior germinação foi oriunda de sementes produzidas com plantas adubados com $32 \mathrm{t} \mathrm{ha}^{-1}$;

As sementes colhidas de plantas adubadas com $60 \mathrm{t} \mathrm{ha}^{-1}$ obtiveram uma maior velocidades de germinação;

Sementes de $S$. indicum produzidas a partir de plantas adubadas com esterco bovino apresentam plântulas mais vigorosas.

\section{Referências}

Barros, M. A.; Santos, R. F.; Benati, T.; Firmino, P. T. Importância econômica e social. In: Beltrão, N. E. M.; Vieira, D. J. (Coord.) O agronegócio do gergelim no Brasil. Brasília: Embrapa Informação Tecnológica, 2001. cap.2, p.21-35. 348p.

Beltrão, N. E. M.; Ferreira, L. L.; Queiroz, N. L.; Tavares, M. S.; Rocha, M. S.; Alencar, R. D.; Porto, V. C. N. O gergelim e seu cultivo no semiárido brasileiro. Natal: IFRN, 2013. 245p.

Beltrão, N. E. M.; Souza, J. G.; Pereira, J. R. Fitologia. In: BELTRÃO,N. E. de M.;VIEIRA, D.J.eds. O agronegócio do Gergelim no Brasil. Brasília: Embrapa Comunicações para transferência de Tecnologia, 2001. cap.3, p.3757.

Beltrão, N. E. M.; Vieira, D. J. O agronegócio do gergelim no Brasil. Brasília: Embrapa Informação Tecnológica, 2001. p.121-160. 348p.

Brasil. Ministério da Agricultura, Pecuária e Abastecimento. Regras para análise de sementes. Brasília: Mapa/ACS, 2009. 399p.

Carvalho, M. A. C.; Arf, O.; Sá, M. E.; Buzetti, S.; Santos, C. B.; Bazzan, D. A. Z. Produtividade e qualidade de sementes de feijoeiro (Phaseolus vulgaris L.) sob influência de parcelamento e fontes de nitrogênio. Revista Brasileira de Ciências do Solo, v. 25, n. 3, p. 617-624, 2001. http://dx.doi.org/10.1590/S0100$\underline{06832001000300010}$

Carvalho, N. M.; Nakagawa, J. Sementes: Ciência, tecnologia e produção. Jaboticabal, FUNEP. 5ed. 2012. 590p.

Cavalcante, L. F.; Pereira, W. E.; Curvêlo, C. R. S.; Nascimento, J. A. M.; Cavalcante, I. H. L.
Estado nutricional de pinheira sob adubação orgânica do solo1 Revista Ciência Agronômica, v.43, n.3, p.579-588, 2012. http://ccarevista.ufc.br/seer/index.php/ccarevista/article/vi $\underline{\underline{e w} / 1622}$

Costa Júnior, A. F. Qualidade fisiológica de sementes de quinoa (chenopodium quinoa willd.) produzidas em solo com diferentes tipos de adubação orgânica. 2017. 40 f. Trabalho de Conclusão de curso submetido à Faculdade de Agronomia e Medicina Veterinária da Universidade de Brasília, Brasília, DF, 2017.

Dossa, K.; Konteye1, M.; Niang, M.; Doumbia, Y.; Cissé, N. Enhancing sesame production in West Africa's Sahel: a comprehensive insight into the cultivation of this untapped crop in Senegal and Mali. Agriculture \& Food Security, v.6, n.68, p.1-15, 2017. http://dx.doi.org/10.1186/s40066-017-0143-3

Dutra, A. S.; Bezerra, F. T. C.; Nascimento, P. R.; Lima, D. C. Yield and seed quality of cowpea as a function of nitrogen fertilization. Revista Ciência Agronômica, v.43, n.4, p.816-821, $2012 . \quad$ http://dx.doi.org/10.1590/S180666902012000400025

Guedes, R. S.; Alves, E. U.; Moura, S. S. S.; Galindo, E. A. Seedling length test in the evaluation of the physiological quality of Amburana cearenses (Allemão) A.C. Smith. Semina: Ciencias Agrarias, v.36, n.4, p.2373$2382, \quad 2015 . \quad$ http://dx.doi.org/10.5433/16790359.2015v36n4p2373

Köeppen, W. Climatologia: con un estudio de los climas de la tierra. Fondo de Cultura. Econômica México: 1948. 478p.

Lacerda, A. L. S. Fatores que afetam a maturação e qualidade fisiológica das sementes de soja (Glycine Max L.). Revista Brasileira de Sementes, v.17, n.1, p.132-137, 2007.

Langham, D. R.; Wiemers, T. Progress in mechanizing sesame in US through breeding In.: Janick, J.; Whipckey, A. (Eds.) Trends in new crops and new uses. Alexandria VA: ASHS Press, 2002. p. 157-173.

Lopes, H. M.; Galvão, J. C. C.; David, A. M. S. S.; Almeida, A. A.; Araújo, E. F.; Moreira, L. B.; Miranda, G. V. Qualidade física e fisiológica de sementes de milho em Função da adubação mineral e orgânica. Revista Brasileira de 
Milho e Sorgo, v.3, n.2, p.265-275, 2004. http://dx.doi.org/10.18512/1980-6477/rbms.v3n02p\%25p

Macedo, A. R.; Pereira, M. D.; Ferreira, E. I.; Soares, E. R.; Zebalos, C. H. S. Qualidade fisiológica de sementes de gergelim produzidas em função da adubação e da lâmina de irrigação. Revista Científica da Faculdade de Educação e Meio Ambiente, v.9, n.1, p.254-265, 2018. http://dx.doi.org/10.31072/rcf.v9i1.572

Magro, F. O.; Arruda, N.; Casa, J.; Salata, A. C.; Cardoso, A. I. I.; Fernandes, D. M. Composto orgânico na produção e qualidade de sementes de brócolis. Ciência e Agrotecnologia, v.34, n.3, p.596-602, 2010. http://dx.doi.org/10.1590/S1413-70542010000300010

Malavolta, E.; Romero, J. P.(Coods). Manual de Adubação. 2 ed. São Paulo: ANDA, 1975. $338 \mathrm{p}$.

Matos, A. K. M. G.; Rosa, L. S.; Pires, H. C. G.; Cabral, B. S.; Vieira, T. A.; Silva, V. M. Morfotipos de frutos e morfologia de plântulas de Attalea maripa (Aubl.) Mart. Ciência Florestal, v.27, n.3, p.819-829, 2017. http://dx.doi.org/10.5902/1980509828632

Mazzani, B. Cultivo y mejoramiento de plantas oleaginosas. Caracas: [s. n.], 1983. p.169-226.

Moreira, W. K. O.; Oliveira, S. S.; Reis, J. S.; Paraense, L. R. C.; Guimarães, A. T.; Silva, R. T. L. Análise de correlação em frutos de Pupunha (Bactris gasipaes Kunth). Global Science and Technology, v.9, n.3, p.106-115, 2016.

https://rv.ifgoiano.edu.br/periodicos/index.php/gst/article/ view/835
Nakagawa, J. Testes de vigor baseados no desempenho das plântulas. In: Krzyzanowski, F. C.; Vieira, R. D.; França Neto, J. B. (Ed.). Vigor de sementes: conceitos e testes. Londrina: ABRATES. p. 1-24, 1999.

Pontes, M. S.; Santiago, E. F.; Nobrega, M. A. S.; Freitas, V. M. B. Caracterização morfológica usando dimensões lineares sobre os atributos biométricos em sementes de Annona reticulata (L.) Vell. (ANNONACEAE). Ciência Florestal, v. 28, n.2, p.696-707, 2018. http://dx.doi.org/10.5902/1980509832070

Quadros, B. R.; Corrêa, C. V.; Magro, F. O.; Cardoso, A. I. I. Influência de composto orgânico e fósforo sobre sementes de alface. Semina: Ciências Agrárias, v.33, n.1, p,25112518, 2012. http://dx.doi.org/10.5433/16790359.2012v33Supl1p2511

Queiroga, V. P.; Silva, O. R. R. F. Tecnologias utilizadas no cultivo do gergelim mecanizado. Campina Grande: Embrapa Algodão, 2008. 142p. (Embrapa Algodão. Documentos, 203).

Queiroga, V.P.; Arriel, N. H. C.; Beltrão, N. E. M.; Silva, O. R. R. F.; Gondim, T. M. S.; Firmino, P. T.; Cartaxo, W. V.; Silva, A. C.; Vale, D. G.; Nóbrega, D. A. Cultivo Ecológico do Gergelim: Alternativa de Produção para Comunidades de Produtores Familiares da Região Semiárida do Nordeste. Campina Grande: Embrapa Algodão, 2007. 53p. (Embrapa Algodão. Documentos, 171). 